\title{
VIOLÊNCIA, RISCO E PROTEÇÃO EM ESTUdANTES DE \\ ESCOLA PÚBLICA \\ http://dx.doi.org/10.1590/1984-0292/853
}

\begin{abstract}
Joyce Hilario Maranhão, Veriana de Fátima Rodrigues Colaço, Walberto Silva dos Santos, Guilherme Sobreira Lopes, João Paulo Lopes Coêlho ${ }^{\star}$
\end{abstract}

Universidade Federal do Ceará, Fortaleza, CE, Brasil

\section{Resumo}

Esse estudo analisou como jovens de escolas públicas identificam e avaliam vivências de violência no ambiente familiar e comunitário, partindo de um recorte de uma pesquisa sobre risco e proteção na população juvenil. Para tanto, foram selecionados 529 estudantes, de 14 a 24 anos e ambos os sexos, que afirmaram ter sofrido algum tipo de violência naqueles ambientes. Aplicou-se um instrumento com 77 questões sobre situações cotidianas e fez-se análise dos itens relativos à vivência de situações de violência. Os resultados demonstraram a ocorrência mais frequente de violência física na familia. Já, na comunidade, ameaça ou humilhação. A percepção negativa dos jovens sobre o ambiente de ocorrência da violência, destacou-se o familiar. Os dados sobre autoestima e autoeficácia revelaram aspectos protetivos. As análises conduzem à conclusão de que a percepção da violência como fator de risco precisa ser compreendida no contexto de participação do jovem e na sua história.

Palavras-chave: juventude; violência; risco; proteção.

\section{VIOLENCE, RISK AND PROTECTION IN STUDENTS FROM PUBLIC SCHOOLS}

\begin{abstract}
This research analyzes how public school students identify and evaluate experiences of violence in a domestic environment and within their communities. This is a snip of a larger research on risk and protective factors in youth populations. Of the 1.140 participants, 529 were students from both genders with ages between 14 and 24 . The results revealed that punching and spanking occurred more frequently in the familiar environment, whereas threatening and humiliation within the community. It was applied a survey with 77 questions concerning those experiences in everyday situations. As for the negative perceptions on the types

\footnotetext{
^Endereço para correspondência: Universidade Federal do Ceará, Centro de Humanidades, Departamento de Psicologia. Av. da Universidade, 2762 - Benfica. 60020181 - Fortaleza, CE - Brasil. E-mail: joyce_hilario@hotmail.com, verianac@gmail.com, walbertosantos@ufc.br, guilherme.s.lopes@hotmail.com,jpcoelhopsi@gmail.com
} 
of abuse regarding the environment where they occurred, the study indicates that undergoing domestic violence had a stronger impact. The results on self-esteem and self-efficacy revealed protective aspects of personal nature. The perception of violence as a risk factor should be understood based on the context of the subject's role and their life story.

Keywords: youth; violence; risk; protection.

A história da sociedade brasileira tem sido atravessada por diferentes formas de violência. Compreender esse fenômeno em seu caráter sociohistórico nos impõe a tarefa de estudar a violência em seus determinantes sociais mais amplos, contextualizando o ato violento a partir dos interesses e valores de cada sociedade ou grupo social em um determinado momento histórico. A violência, como toda prática social, em suas formas de expressão específicas, encontra-se inserida num sistema ideológico e cultural que a possibilita e, por vezes, a torna legítima.

Considerar a violência como um dos aspectos que interferem nas relações entre os indivíduos, requer que a compreendamos como um fator relevante na construção da subjetividade. Como traço potencialmente presente nos diversos tipos de relações interpessoais, ela permeia as interações entre indivíduos e grupos de diversas faixas etárias. Todavia, são as crianças e os adolescentes, em decorrência de sua situação peculiar de desenvolvimento, que apresentam maior vulnerabilidade de sofrerem consequências negativas sobre sua saúde (SANCHEZ; MINAYO, 2006).

O contingente social denominado por Azevedo e Guerra (2011) de "infância vítima de violência" compreende crianças e adolescentes que se encontram em situação de risco pessoal e social, que têm seus direitos básicos violados por omissão ou transgressão da família, da sociedade ou do Estado. Todo ato ou omissão contra crianças e adolescentes implica, de um lado, uma transgressão do poder/dever de proteção por parte do adulto e, de outro, uma coisificação da infância, em franca negação do direito que crianças e adolescentes têm de serem tratados como sujeitos em condição peculiar de desenvolvimento (AZEVEDO; GUERRA, 2011).

No que se refere à juventude, segmento social foco dessa investigação, é notório que a violência está presente, de forma direta ou indireta, nas relações familiares, comunitárias e institucionais. A violência contra jovens se configura a partir de um entrelaçamento de fatores estruturais e históricos das dinâmicas extra e intrafamiliares, quase sempre "baseadas na hierarquia, na subordinação, no poder e na obediência" (OSTERNE, 2001, p. 54). Especificamente, a violência doméstica ou intrafamiliar se constrói e se mantém através da conservação de padrões assimétricos nas relações de gênero e inter-geracionais (AZEVEDO; GUERRA, 2011).

A violência integra os espaços de socialização de adolescentes e jovens, apresentando-se como fator de risco, em um determinado momento da vida, expondo-os a situações de vulnerabilidade. Essas vivências podem trazer consequências tanto físicas quanto psicológicas, acarretando prejuízos ao seu desenvolvimento e à percepção positiva de si. No entanto, uma situação de violência 
nem sempre é percebida como risco, uma vez que cada sujeito experiencia e significa a realidade de forma distinta, devendo-se considerar na análise das situações de risco e vulnerabilidade as dimensões cultural e subjetiva.

Dependendo do contexto e do tipo de sociedade, a violência pode ser observada a partir de diversos ângulos e discursos, logo, sua análise considera o significado construído nas relações desenvolvidas entre o sujeito e o seu ambiente. Aspectos culturais emprestam valores e sentidos a atos que, vistos isoladamente, podem ser interpretados ou como de extrema violência ou como atos banais e ou aceitáveis, embora, em sendo violentos, são danosos e trazem sofrimento.

A discussão sobre os fatores de risco envolvidos nos contextos de violência costuma vir acompanhada do debate em torno dos fatores de proteção. A proteção está relacionada a competências e recursos psicológicos, sociais e institucionais, que permitem ao sujeito o enfrentamento de situações adversas. Esses fatores não estão dados de forma apriorística no ambiente, nem, simplesmente, no "interior" dos indivíduos; eles são construídos a partir da relação do sujeito com seu entorno - familiares, amigos, colegas de escola, vizinhos, professores, suportes institucionais e outros.

Os recursos de proteção podem ser de ordem pessoal, tais como sentimentos de autoestima, autoeficácia, autoconfiança, confiança no outro e boa perspectiva de futuro, que contribuem para uma percepção positiva de si, bem como no âmbito social, relacionados diretamente com os vínculos afetivos na família e na comunidade da qual participa. Segundo Libório e Castro (2009), a análise das relações entre os indicadores de risco e proteção depende do modo como estão integrados à história do indivíduo; é o modo como interagem que pode interferir na trajetória de vida do sujeito, favorecendo ou dificultando o seu desenvolvimento saudável.

Por fim, acrescenta-se à nossa discussão o conceito de resiliência, que pode ser definido como o processo no qual os fatores de risco e os fatores de proteção estão presentes e interagindo entre si em um determinado momento da vida. $\mathrm{O}$ resultado desse processo dinâmico e situado cultural e historicamente, é a superação da situação de adversidade (YUNES; SZYMANSKI, 2001). A capacidade de resiliência estaria, portanto, associada tanto a processos intrapsíquicos como sociais, que possibilitariam o desenvolvimento sadio, mesmo diante de experiências de vida traumáticas (ASSIS; PESCE; CARVALHAES, 2006).

A resiliência não se confunde com um meio de evitar ou eliminar o fator de risco, antes é um modo de lidar com circunstâncias desfavoráveis e prejudiciais ao indivíduo a partir de referências pessoais e coletivas (YUNES; SZYMANSKI, 2001). Por conseguinte, envolve a interação entre adversidade e fatores de proteção internos e externos aos sujeitos, que os permitem fazer frente às situações difíceis presentes na vivência cotidiana. Não obstante, estar exposto a situações que podem configurar-se como situação de vulnerabilidade, a exemplo da violência, não significa que os jovens não possam criar diferentes formas de enfrentamento a circunstâncias adversas (YUNES, 2003), uma vez que há 
processos que possibilitam a resiliência do jovem a partir de uma rede complexa de proteção constituída por contextos como: família, comunidade, instituições públicas e privadas e aspectos subjetivos positivos.

Neste trabalho, adotamos uma compreensão dialética da relação entre risco e proteção a partir dos pressupostos vygotskianos acerca da matriz histórico-cultural do desenvolvimento humano. Para Vygotsky (1995[1927], 2007), o desenvolvimento humano se configura como um processo ativo de adaptação do indivíduo ao meio, por uma interação constante e, mutuamente, constitutiva entre sujeito e cultura. A pessoa não é uma entidade isolada, tampouco está livre das influências do ambiente, mas se constitui na interdependência entre a sua individualidade e as relações sociais que estabelece.

A contribuição central da teoria de Vygotsky para uma compreensão histórico-cultural das subjetividades reside na consideração da cultura como categoria constitutiva do desenvolvimento e do próprio psiquismo humano. Ao eleger a cultura como fator que possibilita a emergência das funções psicológicas superiores, ele afirmou que tanto a consciência quanto outros processos mais complexos são, em síntese, relações sociais mediadas simbolicamente, caracterizando, dessa forma, o desenvolvimento psíquico como desenvolvimento cultural (VYGOTSKY, 2007)

No processo de construção social dos processos mentais, a linguagem assume função central, constituindo-se como principal meio interativo com os demais participantes da cultura. É mediante os processos interativos da comunicação com outros seres humanos que as subjetividades dos indivíduos são constituídas no desenrolar do desenvolvimento. Tais características, tipicamente humanas, surgem através da construção dessas relações entre os sujeitos e, em um dado momento, são convertidas em processos intrapsíquicos, tornando-se processos individuais.

É somente no compartilhamento das experiências do indivíduo com o outro e vice-versa que é possível a internalização de valores e sentimentos que contribuem para a socialização das pessoas. Essa socialização ocorre, basicamente, por meio da linguagem. É a utilização dos signos como mediadores da ação humana que colabora para a apropriação do coletivo e, posteriormente, para o domínio de si mesmo. O homem tem a capacidade de simbolizar suas ações e planejar suas atividades futuras. Atribuir sentido às situações vivenciadas permite que se criem maneiras de se posicionar no mundo, ou seja, proporciona a organização e a apropriação das experiências formadoras de seu desenvolvimento.

Para Libório e Castro (2009), as vivências, os sentidos e as oportunidades às quais estão expostos os adolescentes e jovens decorrem ainda do momento da história de vida, de sua inserção de classe social, etnia e de sua condição de gênero. Cada pessoa age de forma singular frente às situações de vulnerabilidade social, de acordo com suas competências, seus recursos psíquicos e seu suporte social disponível, todos esses mecanismos de proteção irão se articular com a história particular de cada um e suas condições concretas de existência para a superação da situação de risco. 
Assim, a presente pesquisa foi realizada no intuito de analisar como os adolescentes e jovens de escolas públicas do município de Fortaleza identificam e avaliam a vivência da violência no ambiente familiar e comunitário, assim como a relação entre essa experiência e os fatores protetivos pessoais e sociais.

\section{MÉTOdo}

\section{Amostra}

Este trabalho está vinculado à pesquisa Adolescência e Juventude: situação de risco e redes de proteção na cidade de Fortaleza ${ }^{1}$ realizada no período de janeiro de 2009 a julho de 2011, que contemplou 1.140 estudantes com idade entre 14 a 24 anos, de ambos os sexos, nível socioeconômico baixo e que frequentavam, à época, o Ensino Fundamental, Médio e Educação de Jovens e Adultos (EJA) em 43 escolas públicas da rede estadual e municipal de ensino de Fortaleza. As instituições foram escolhidas aleatoriamente, contemplando todas as seis regionais do município.

Para este estudo específico, foram selecionados 529 estudantes que responderam afirmativamente a, pelo menos, um dos itens do instrumento que indicavam violência na família e/ou na comunidade. Não obstante, foram analisadas as respostas dos jovens nos itens sobre os fatores protetores sociais, tais como: apoio familiar, clima e controle familiar, e os pessoais, a exemplo de: percepção de oportunidades futuras, autoeficácia e autoestima. Especificamente, os participantes tinham entre 14 e 24 anos $(m=16,76 ; d p$ $=2,15)$, dos quais $90,9 \%$ concentraram-se na faixa etária entre 14 e 19 anos, sendo a maioria do sexo feminino $(54,6 \%)$ e solteira $(91,5 \%)$. A maioria dos estudantes se declarou de cor parda $(62,4 \%)$ e, entre as declarações nas demais categorias, os porcentuais foram: $18,1 \%$ brancos, $12,1 \%$ negros, $3 \%$ amarelos e $4 \%$ indígenas, $0.4 \%$ não responderam. Quanto à renda familiar, $62,8 \%$ dos jovens não souberam responder e, dos que responderam ao item $(\mathrm{n}=196), 45,4 \%$ afirmaram ter renda familiar de um a dois salários mínimos, $40,3 \%$ apontaram renda acima de dois salários mínimos e 14,3\% ser de até um salário mínimo, $0,2 \%$ não respondeu.

\section{Instrumento}

Após a aplicação de um instrumento-piloto para validação do questionário, aplicou-se o Questionário da Juventude Brasileira - Versão II (DELL'AGLIO et al., 2011). O instrumento foi composto por 77 questões que caracterizam o perfil geral de jovens. Para tanto, as questões versavam sobre situações cotidianas, sendo algumas com opção de respostas nominal e outras em escalas Likert de cinco pontos sobre intensidade e frequência. Especificamente, este instrumento se propôs a avaliar fatores de risco e de proteção em adolescentes e jovens, abordando aspectos relacionados à educação, família, sexualidade, saúde, trabalho; comportamentos de risco (drogas, suicídio, violência); fatores de risco (violência intrafamiliar e na comunidade, exposição às doenças/drogas, deficiência, discriminação, institu- 
cionalização, vida na rua, conflito com a lei, empobrecimento/pobreza, separação/ perda na família); e fatores protetores sociais (lazer, rede de apoio) e pessoais (espiritualidade, autoestima, autoeficácia, perspectivas para o futuro).

Destes aspectos, podem-se citar itens relacionados à religiosidade ("Costumo fazer orações no dia-a-dia" e "Sigo recomendações religiosas na minha vida diária"), que deveriam ser respondidos em escala Likert de cinco pontos (1 $=$ Nunca e $5=$ Sempre) e à relação familiar ("Meus pais raramente brigam entre eles" e "Eu me sinto seguro com meus pais"), avaliados em escala Likert, em que 1 = Discordo totalmente e $5=$ Sempre. No que diz respeito aos componentes que compõem a relação familiar (apoio, controle e clima familiar), podem-se citar "eu me sinto aceito pelos meus pais", "meus pais conhecem meus amigos" e "meus pais raramente me criticam", respectivamente. Ademais, dentre os itens referentes à autoestima, podem-se citar "às vezes, eu me sinto inútil" e "eu sinto vergonha de ser do jeito que sou" e, no que se refere à autoeficácia, este foi composto por itens como "se estou com problemas, geralmente encontro uma saída" e "eu geralmente consigo enfrentar qualquer adversidade". Para a análise destes construtos, considerou-se "Baixo" as pontuações 1 e 2, Médio a pontuação 3, e Alto as pontuações 4 e 5 da escala.

\section{Procedimento}

A aplicação do questionário foi realizada de forma coletiva, em turmas de, no máximo, 35 estudantes, com a assistência de um pesquisador e dois auxiliares membros da equipe. Os requisitos éticos foram atendidos com o esclarecimento dos objetivos e da metodologia da pesquisa, bem como pela concordância dos participantes, formalizada mediante consentimento assinado pelos pais ou responsáveis dos estudantes menores de idade ou pelos próprios, no caso daqueles de 18 anos ou mais.

A necessidade da autorização formal dos pais ou responsáveis para a participação da pesquisa por uma parte dos sujeitos composta por adolescentes de 14 a 18 anos incompletos, implicou mudanças na escolha das escolas, assim como requereu várias visitas as mesmas, a fim de que se completasse o número de questionários necessários para a amostra. Esta alteração gerou a necessidade de estender o período de coleta de dados, que só pôde ser finalizado em julho de 2010, sendo analisados em 2011. A pesquisa foi submetida e aprovada pelo Comitê de Ética da Universidade Federal do Ceará.

\section{Análise dos dados}

A análise dos dados foi realizada por meio do software SPSS, versão 18. Por meio de análises descritivas, foram avaliadas frequências e porcentagens das respostas dos itens do instrumento relativos à vivência de situações de violência no ambiente familiar e comunitário, bem como comparadas as médias, por meio de testes $t$ de Student, dos diferentes tipos de abusos vivenciados por adolescentes e jovens. 


\section{Resultados E DiscuSsão}

O recorte deste estudo toma como referência duas perguntas do questionário relativas à vivência de situações de violência no ambiente familiar e comunitário. Na Tabela 1 são apresentados os casos que indicam violência sofrida pelos adolescentes e jovens na família e na comunidade. Entre os três tipos de violência indicados pelo questionário, a saber, ameaça ou humilhação, soco ou surra e agressão com objeto, a ocorrência de soco ou surra foi a mais frequente na família $(35,5 \%)$, enquanto na comunidade a violência que mais se repete é a ameaça ou humilhação $(22,5 \%)$.

Tabela 1- Frequência de casos de violência ocorridos na família e na comunidade.

\begin{tabular}{lcccc}
\hline \multirow{2}{*}{ Tipo de Violência } & \multicolumn{2}{c}{ Família } & \multicolumn{2}{c}{ Comunidade } \\
\cline { 2 - 5 } & $N$ & $\%$ & $N$ & $\%$ \\
\hline Ameaça ou humilhação & 97 & 18,3 & 119 & 22,5 \\
Agressão com objeto & 171 & 32,3 & 22 & 4,2 \\
Soco ou surra & 188 & 35,5 & 54 & 10,2 \\
\hline
\end{tabular}

A ocorrência mais frequente das agressões físicas contra os jovens no ambiente doméstico aponta para uma demonstração do quanto é enraizado na sociedade brasileira o uso da punição corporal sob a justificativa de educar e impor limite ao comportamento dos filhos pelos pais. Esse tipo de prática é refletido na Tabela 2: apresenta quem são os perpetradores das agressões sobre os quais os jovens foram indagados. Eles apontaram os genitores como os agressores mais frequentes da violência intrafamiliar, especialmente a mãe.

Tabela 2- Perpetradores das agressões da família e da comunidade

\begin{tabular}{|c|c|c|c|c|c|c|}
\hline & \multicolumn{2}{|c|}{$\begin{array}{l}\text { Ameaça ou } \\
\text { humilhação* }\end{array}$} & \multicolumn{2}{|c|}{ Soco ou surra* } & \multicolumn{2}{|c|}{ Agressão* } \\
\hline & $N$ & $\%$ & $N$ & $\%$ & $N$ & $\%$ \\
\hline \multicolumn{7}{|l|}{ Família } \\
\hline Mãe & 52 & 25,4 & 105 & 44,5 & 85 & 49,4 \\
\hline Madrasta & 2 & 1,0 & 0 & 0 & 1 & 0,6 \\
\hline Pai & 50 & 24,4 & 65 & 27,5 & 58 & 33,7 \\
\hline Padrasto & 15 & 7,3 & 5 & 2,1 & 5 & 2,9 \\
\hline Irmãos & 31 & 15,1 & 27 & 11,4 & 12 & 7 \\
\hline Avós & 9 & 4,4 & 6 & 2,5 & 2 & 1,2 \\
\hline Outros & 46 & 22,4 & 28 & 20 & 9 & 5,2 \\
\hline \multicolumn{7}{|l|}{ Comunidade } \\
\hline Amigos & 52 & 24,4 & 26 & 23,6 & 4 & 11,4 \\
\hline Colegas de escola & 49 & 23,0 & 31 & 28,2 & 3 & 8,6 \\
\hline Vizinhos & 12 & 5,6 & 5 & 4,5 & 3 & 8,6 \\
\hline Professores/Monitores & 5 & 2,3 & 0 & 0 & 0 & 0 \\
\hline Policias & 8 & 3,8 & 3 & 2,7 & 3 & 8,6 \\
\hline Desconhecidos & 59 & 27,7 & 32 & 29,1 & 13 & 37,1 \\
\hline Outros & 28 & 13,1 & 13 & 11,8 & 9 & 25,7 \\
\hline
\end{tabular}


$\mathrm{Na}$ comunidade, os agressores recorrentes foram principalmente pessoas desconhecidas. Contudo, se destaca a posição ocupada pelos amigos e colegas de escola, que se seguem a pessoas desconhecidas. Eles foram os responsáveis por perpetrarem com maior frequência ameaça ou humilhação $(24,4 \%)$, e soco ou surra $(28,2 \%)$, respectivamente.

Segundo Amparo et al. (2008), os laços afetivos com amigos e colegas de escola colaboram para a proteção e para a constituição da identidade do sujeito, na medida em que são um meio de obtenção de suporte emocional, espiritual, material e social, pois os jovens compartilham angústias, descobertas, sonhos e sentimentos próprios dessa etapa da vida. No entanto, ressalta-se, a partir dos resultados expostos na Tabela 2, que as relações entre os jovens podem estar fragilizadas devido à presença da violência, haja vista terem apresentado índices expressivos na perpetração de agressões verbais (ameaça ou humilhação) e físicas (soco ou surra). O cotidiano desses jovens pode estar sendo afetado de forma negativa por tais circunstâncias, o que prejudica e limita a construção dessas relações de confiança e cuidado entre esses sujeitos. Apesar de alguns agressores terem sido apontados com maior frequência em alguns tipos de abuso, é possível observar que a perpetração da violência está diluída entre todos os indivíduos elencados pelo questionário, o que nos dá indícios de que a violência é uma questão estrutural, histórica e cultural, como apontam vários autores (CHAUÍ, 2007; FALEIROS, V.; FALEIROS, E., 2007; OSTERNE, 2001; WAISELFISZ, 2011).

Referente aos resultados sobre os fatores protetores pessoais (Tabela 3), os índices de respostas afirmativas aos itens foram elevados; $72 \%$ dos adolescentes afirmaram ter uma autoestima positiva, $69,8 \%$ se perceberam como capazes para realizar qualquer tipo de atividade e $74,5 \%$ tiveram uma boa expectativa quanto a oportunidades futuras. Tais fatores são relevantes, pois contribuem para a formação de uma imagem positiva de si, para o sentimento de autoconfiança e de autoeficácia tanto para a realização de atividades como para a resolução de situações difíceis e inesperadas. Os indicadores de proteção pessoais estão diretamente interligados ao processo de resiliência, à medida que contribuem para o desenvolvimento das capacidades e dos recursos psicológicos necessários para o enfrentamento de eventos estressores do cotidiano dos jovens, minimizando os efeitos negativos dos fatores de risco.

Tabela 3- Níveis de fatores de proteção de ordem pessoal e social.

\begin{tabular}{lcccccc}
\hline \multirow{2}{*}{\multicolumn{1}{c}{ Fatores de Proteção }} & \multicolumn{2}{c}{ Baixa } & \multicolumn{2}{c}{ Média } & \multicolumn{2}{c}{ Alta } \\
\cline { 2 - 7 } & $N$ & $\%^{*}$ & $N$ & $\%^{*}$ & $N$ & $\%^{*}$ \\
\hline Pessoais & & & & & & \\
Autoestima & 128 & 28 & 236 & 51,4 & 96 & 20,6 \\
Autoeficácia & 136 & 30,2 & 211 & 47,5 & 99 & 22,3 \\
Percepção de oportunidades futuras & 120 & 25,3 & 257 & 54,5 & 94 & 20 \\
\hline
\end{tabular}




\begin{tabular}{|c|c|c|c|c|c|c|}
\hline \multirow{2}{*}{ Fatores de Proteção } & \multicolumn{2}{|c|}{ Baixa } & \multicolumn{2}{|c|}{ Média } & \multicolumn{2}{|c|}{ Alta } \\
\hline & $N$ & $\% *$ & $N$ & $\% *$ & $N$ & $\% *$ \\
\hline Sociais & & & & & & \\
\hline Apoio familiar & 141 & 28,3 & 251 & 50,4 & 106 & 21,3 \\
\hline Clima familiar & 144 & 29 & 237 & 48 & 114 & 23 \\
\hline Controle familiar & 153 & 29,5 & 365 & 70,5 & - & - \\
\hline Pertencimento à comunidade & 126 & 26,3 & 245 & 50,8 & 111 & 22,9 \\
\hline
\end{tabular}

Nota: *Valores obtidos a partir dos casos válidos, desconsiderando os que não responderam (missing).

Sobre os fatores protetores sociais, a maioria dos adolescentes afirmou receber apoio da família (71,7\%), e ter clima familiar positivo, 71\%. Apesar de nenhum dos jovens afirmarem ter um controle familiar alto, o índice dos participantes que afirmaram ter controle familiar médio foi significativo, 70,5\%. A partir desses dados, percebe-se que a família ainda mantém sua função de proteção, cuidado e formação do indivíduo, ainda que, pelos índices de prática de violência doméstica observados, o ambiente familiar também se apresente como espaço de risco e vulnerabilidade.

Um aspecto importante é que, ao serem comparadas as percepções negativas dos jovens sobre os tipos de abusos em relação ao ambiente onde ocorreu a situação, observou-se que, em todos os itens, foi mais significativo sofrer a violência no ambiente familiar do que na comunidade (Ameaça ou humilhação, $t=$ $3,50, p \leq 0,001$; Agressão com objeto, $t=2,11, p \leq 0,05$; Soco ou surra $t=1,97$, $p \leq 0,05)$. A percepção da situação de violência no ambiente familiar de forma mais negativa pode estar relacionada ao fato de que a família ainda é considerada como um locus de referência para o jovem, tornando a significação dessa vivência psicologicamente mais dolorosa.

Ademais, é importante salientar que os elementos que dispomos devem ser tomados apenas como indicadores que nos ajudam a entender o fenômeno da violência intrafamiliar de maneira generalizada. Uma compreensão mais profunda e detalhada das relações entre pais e filhos exige uma complexidade analítica que foge ao alcance de uma pesquisa com esse tipo de abordagem metodológica. Os filhos podem desenvolver as mais diversas representações acerca de seus genitores, sendo construídas significações que irão se articular e/ou se sobrepor a partir de uma lógica coerente com suas experiências cotidianas. Considerando os dados apresentados na Tabela 3, somou-se a porcentagem dos adolescentes e jovens que responderam ao item 'Pertencimento à comunidade' como sendo médio e alto, $50,8 \%$ e $22,9 \%$, respectivamente, resultando num total de $73,7 \%$. Desse resultado, inferiu-se que há laços de afetividade e confiança deles com vizinhos e organizações/instituições comunitárias (escola, posto de saúde, instituições ligadas à religião, esporte e cultura, etc.).

Afirmar-se como participante de uma comunidade, além de demonstrar certo envolvimento com os outros moradores, indica que o sujeito de alguma forma se identifica com os hábitos daquele lugar. Desenvolver sentimento de per- 
tencimento e segurança vinculados a um determinado local, bem como saber que pode contar com ajuda de seus moradores, causa repercussões sobre a subjetividade do jovem e facilita a construção de uma visão positiva do bairro onde habita.

\section{VIOLÊNCIA: CONDIÇÃo DE RISCO E RECURSOS DE PROTEÇÃo}

Os dados encontrados neste estudo apontam para uma compreensão da realidade social na qual esses jovens se encontram. A relação entre situações de violência, considerada como risco e fatores protetores sociais e pessoais configura um ambiente permeado por situações adversas ao desenvolvimento, ao mesmo tempo em que pode se estruturar uma rede de apoio a esses jovens em seus desafios cotidianos. Isso demonstra que, longe de ser uma qualidade inata, a condição de enfrentamento das adversidades, que seria considerada como resiliência, é resultado de uma articulação complexa entre situações que ao mesmo tempo em que expõem o indivíduo a uma condição de risco, o instrumentaliza e acentua circunstâncias que promovem a sua proteção. A ocorrência de um fator não elimina o outro, mas é o jogo de equilíbrio entre eles que provoca a ação do sujeito frente ao ambiente, de acordo com o horizonte de possibilidades vislumbradas por ele.

Na concepção vygotskiana de homem, por exemplo, o indivíduo está em constante relação com o outro, sendo influenciado e influenciando o meio em que vive (VYGOTSKY, 2007). É na relação com o outro que nos reconhecemos como indivíduos, isto é, nos construímos subjetivamente nas relações intersubjetivas mediadas por signos e instrumentos (DRANKA, 2001). O contato com o outro permite a aprendizagem e o compartilhamento de valores éticos e morais, bem como o respeito ao desejo/vontade do outro e o conhecimento dos limites da sua vontade, essa relação entre os indivíduos é recíproca. Para Costa e Bigras (2007), a função do adulto é auxiliar os jovens na adoção de comportamentos saudáveis para o desenvolvimento, na construção de sentimentos de confiança em si e nas outras pessoas, enfim, no estabelecimento de competências e emoções necessárias para o convívio em sociedade. A família, os amigos, a comunidade e a escola compõem uma rede de apoio que exerce papel fundamental na proteção dos jovens, pois lhes disponibilizam sentimentos e competências que contribuem para uma ação frente a situações adversas. Autoestima, autoeficácia, autonomia, empatia e confiança em si e no outro são valores aprendidos nas relações intersubjetivas e internalizados pelo indivíduo que, uma vez presentes e integrados, transformam-se em mecanismos de proteção, possibilitando ao indivíduo a organização de estratégias para resolução e superação dos problemas.

O Estatuto da Criança e do Adolescente (BRASIL, 1990), em seu artigo $4^{\circ}$, aponta que a proteção e a promoção de um desenvolvimento saudável através do acesso a uma boa qualidade de vida, à alimentação, à educação, ao convívio familiar e comunitário são direitos dos jovens, e a efetivação deles é de responsabilidade da família, da comunidade, da sociedade e do poder público. O fato de os pais aparecerem como os agressores mais frequentes da violência doméstica encontra correspondência em outras pesquisas de âmbito nacional (ANTONI; 
KOLLER, 2000; AZEVEDO; GUERRA, 2011; GOMES et al., 2002; BRITO et al., 2005), evidenciando que o uso abusivo da força física e do autoritarismo surge, frequentemente, como meio prático de educação dos filhos.

A violência na família, caracterizada pela assimetria e hierarquização das relações interpessoais, estrutura-se dentro de uma dinâmica relacional marcada pela desigualdade e subordinação dos membros. A família brasileira se constitui a partir de uma cultura "adultocêntrica", dominadora e patriarcal, sendo, portanto, locus privilegiado das desigualdades de gênero e geração, que têm legitimado o domínio autoritário dos pais e dos adultos sobre crianças e adolescentes (SANCHEZ; MINAYO, 2006). Como os demais atos violentos, este encontra significado no contexto específico de nossa sociedade. A partir da década de 1980, a violência doméstica ou intrafamiliar, em especial a direcionada à criança e ao adolescente, tem ganho visibilidade e sido alvo de proteção do Estado com políticas públicas específicas. Entretanto, apesar dos avanços sociais relativos a essa temática e da luta por parte dos movimentos em defesa dos direitos de crianças e adolescentes, como afirma Brito et al. (2005, p.146),

Na sociedade brasileira atual, o uso da punição física é ainda um instrumento bastante frequente na educação dos filhos. Os pais tendem a defender essa forma de disciplina que, em determinadas circunstâncias, pode favorecer a banalização e a cronicidade da violência física doméstica contra crianças e adolescentes. Observamos que, para alguns pais, inclusive para alguns profissionais, tais atos, por não serem considerados práticas abusivas, serão reproduzidos como uma prática normal de disciplinamento.

A violência intrafamiliar tem sido naturalizada em nossa sociedade pela vinculação do sentido de responsabilidade sobre os filhos com o autoritarismo, utilizando a punição como meio para educar e incutir valores morais, o que indica uma "transgressão no poder/dever de proteção do adulto e da sociedade em geral” (MINAYO, 2001 apud FALEIROS, V.; FALEIROS, E., 2007, p. 31). Na maioria das vezes, a violência doméstica acontece sob uma pretensa atitude educativo-disciplinar, sendo que, em nome da disciplina e da obediência, crianças e jovens são maltratados (GOMES et al., 2002). No imaginário social brasileiro, é forte a crença de que a melhor educação deve se pautar por punição e humilhação, e persiste a ideia da violência física como atitude legítima para a contenção da desobediência e da rebeldia de jovens (SANCHEZ; MINAYO, 2006). Nesse contexto, como afirmam Azevedo e Guerra (2011), o abuso físico expresso nos maus tratos surge como produto esperado de uma sociedade que incorpora a força física como um método de educação e controle.

No que se refere aos dados relativos à percepção negativa sobre os atos de violência (ameaça ou humilhação, agressão com objeto e soco ou surra) sofridos, os jovens apontaram que violência sofrida no ambiente familiar é significada de forma mais negativa do que a violência sofrida na comunidade. É constatado que, mesmo num contexto de banalização do uso de violência física e psicológica como 
práticas educativa-disciplinares, esse tipo de violência perpetrado contra jovens não deixa de exercer efeitos danosos sobre seu desenvolvimento, sendo considerado, portanto, fator de risco. Um dado importante a ser analisado é que, mesmo diante de uma realidade de maus-tratos e abusos por parte de familiares, a família ainda aparece como espaço de referência e apoio para os jovens. Em parte, isso pode ser justificado, segundo Bruschini (2011), pelo fato de a família, em seus moldes atuais, se configurar também como um lugar de refúgio, de afetividade, onde se estabelecem sentimentos entre o casal e os filhos, além de um lugar (bom ou mau) de atenção à infância. Precisamente, na contemporaneidade, se firma essa concepção da família como lugar de recolhimento e defesa dos indivíduos, cabendo a ela o papel (quase exclusivamente feminino) de zelar pelo bem-estar físico e emocional de seus dependentes (AZEVEDO; GUERRA, 2011).

\section{Considerações Finais}

O que vemos em comum a todas as formas de expressão de violência, seja física ou psicológica, são os aspectos de poder, hierarquia, medo, submissão e cerceamento da vontade do outro nas relações intersubjetivas. Deste modo, a violência deve ser compreendida como um fenômeno social complexo que envolve aspectos estruturais e relacionais da sociedade, estando longe de ter apenas uma dimensão individual (WAISELFISZ, 2011).

Na situação de violência, há um silenciamento da vontade do indivíduo (DRANKA, 2001), as suas escolhas são cerceadas em favor do que o outro the aponta como o correto, seja por meio da agressão verbal ou física, o que pode vir a interferir de forma decisiva na construção da sua subjetividade e da identidade positiva de si. De acordo com Chauí (2007, online), a violência é uma prática/ ideia que "reduz um sujeito à condição de coisa, que viola interior e exteriormente o ser de alguém, que perpetua relações sociais de profunda desigualdade econômica, social e cultural".

Para a autora, a sociedade brasileira ainda conserva as marcas da sociedade colonial escravista, caracterizada pelo predomínio do espaço privado sobre o público, tendo como modelo de base a organização familiar em que as relações sociais intersubjetivas são desiguais, estando organizadas através da superposição de "um superior, que manda, e um inferior, que obedece" (CHAUí, 2007, online), ou seja, não há uma reciprocidade entre os indivíduos. Nessa relação desigual, o outro não é reconhecido como um sujeito de direitos; assim, fica enfraquecida a percepção da agressão física, verbal e psicológica contra os jovens como uma violência, o que permite uma naturalização dessa circunstância tanto pelos agressores como pelas vítimas. Entretanto, essa ofuscação da violência de modo algum anula as consequências físicas e psíquicas negativas para os que a vivenciam.

Os resultados das análises deste estudo sinalizam a violência doméstica como indicador de maior ocorrência e significado negativo na vivência dos jovens participantes, apesar de suas condições contextuais de precariedade, aviltamento 
de direitos e reconhecimento de violência sofrida no ambiente comunitário. Isso levanta alguns questionamentos acerca da complexidade desse fenômeno, que é, de modo geral, atribuído às relações que se estabelecem fora do âmbito familiar.

Compreendemos que o que faz com que a violência se configure como um fator de risco não é apenas o fenômeno em si, mas a forma como ela é experimentada e, consequentemente, significada pelo indivíduo que a sofre. A significação dada a essa vivência é relevante, pois é esse sentido intrapsíquico que orientará a vida do sujeito e permitirá a construção ou não de condições para a superação de suas marcas. Segundo Cyrulnik (2006), a atribuição de sentido é um caminho para que a pessoa possa falar o porquê da situação ter acontecido com ela. Mais do que isso, para que a pessoa possa falar sobre o ocorrido para o outro e para si mesma. Deste modo, a construção de sentido se dá pelas representações verbais compartilháveis das imagens e das emoções sentidas, devolvendo-lhes o sentido de ser.

A significação das experiências contribui, também, para reações resilientes, ao permitir que o indivíduo lance outro olhar sobre os eventos estressores ocorridos em sua vida e possa lidar com eles de forma mais integrada. No caso da situação de violência, a sua ressignificação permite que a pessoa construa uma concepção mais positiva de si. A discussão da percepção da violência como um fator de risco precisa ser entendida a partir de um contexto mais amplo, onde estão envolvidos aspectos históricos, sociais, culturais e estruturais. Ao mesmo tempo, é nas relações afetivas e sociais estabelecidas com as outras pessoas que construímos nossa identidade como seres singulares, com nossas próprias aspirações. Quando essas relações encontram-se fragilizadas devido à presença de um fator de vulnerabilidade e risco, como é o caso da violência, o sujeito pode ter seu desenvolvimento comprometido.

Os mecanismos de proteção advindos da família e da comunidade em geral contribuem para o fortalecimento de uma identidade positiva, para um sentimento de autoestima, autoeficácia e confiança em si e no outro e para a organização de estratégias para o enfrentamento de dificuldades. Ao tratar de fatores que promovem proteção ou que causam risco, é preciso ter em vista que essas condições não estão dadas de forma concreta no ambiente, esses fatores não agem sozinhos, eles se articulam entre si e com a história de vida do sujeito e principalmente com o momento vivenciado por ele. Mesmo quando se faz referência a valores, hábitos culturais e aprendizagens largamente difundidas em uma dada cultura, acreditamos que a apropriação dessas habilidades por cada sujeito em seu processo de socialização se dá de forma particular. Inclusive quando os indivíduos passam por situações similares típicas de um determinado agrupamento cultural, a maneira como as experienciam é, também, particular, sendo esse um dos fatores da heterogeneidade típica das subjetividades humanas.

Tentar compreender a relação entre a experiência da situação de violência e os fatores protetores pessoais e sociais é aventurar-se por um caminho complexo, pois não se trata de apenas analisar dados concretos, mas de pressupor esses indicadores de violência em uma conjuntura mais ampla, que adquire certo sentido na realidade dos sujeitos participantes do estudo. Sem dúvida, sofrer algum tipo de 
ameaça ou humilhação e de agressão física repercute na identidade e na percepção de si como um sujeito autônomo que tem seus próprios desejos e possui direitos que devem ser respeitados. No entanto, é indispensável ampliar os olhares para os acontecimentos na história de vida do indivíduo que o permitirão elaborar ou melhorar as estratégias diante da situação adversa, bem como ressignificar a experiência da violência a que foi exposto, para superá-la. Pelo que se pode analisar, o fato desses jovens terem sofrido agressões não os torna mais vulneráveis ou menos capazes de lidar com outras situações adversas, tampouco os torna mais resilientes; o mais importante é buscar apreender o modo como esses abusos irão repercutir no processo de subjetivação, o que dependerá da presença e da articulação dos aportes emocionais e sociais na vida de cada indivíduo.

A partir do dado sobre a percepção negativa da violência ter sido mais significativa na família do que na comunidade, supõe-se que o ambiente familiar ainda exerce função central na formação e na proteção dos indivíduos, daí a violência comprometendo os vínculos familiares ser percebida de forma mais clara e mais dolorida psiquicamente pelos jovens. Por fim, viver em um ambiente onde a violência pode estar presente não significa que o desenvolvimento do indivíduo será marcado somente por essa experiência. As relações intersubjetivas são bem mais complexas e o entrelaçamento das experiências compartilhadas com o outro e a vontade do sujeito irão sempre atuar em conjunto na orientação da sua trajetória de vida.

Por fim, destaca-se que a compreensão dos aspectos observados acerca da percepção da violência no ambiente familiar e comunitário, bem como a existência de fatores protetivos nesses espaços de socialização, não se explicita pelos índices encontrados, merecendo enfoque de análise de cunho qualitativo. Ainda, a limitação da coleta de dados devido a maior parte do público participante ser composta por adolescentes entre 14 e 18 anos incompletos, necessitando de autorização formal dos pais ou responsáveis para participar da pesquisa, dificultou na ampliação da amostra.

\section{Nota}

${ }^{1} \mathrm{O}$ relatório técnico da pesquisa pode ser acessado no site www.pospsi.ufc.br.

\section{REFERÊNCIAS}

AMPARO, D. M et al. Adolescentes e jovens em situação de risco social: redes de apoio social e fatores pessoais de proteção. Estudos de Psicologia, v. 13, n. 2, p. 165-174, 2008.

ANTONI, C.; KOLLER, S. H. A visão de famílias entre as adolescentes que sofreram violência intrafamiliar. Estudos de Psicologia, [S.1.], v. 5, n. 2, p. 347$381,2000$.

ASSIS, S. G.; PESCE, R. P.; CARVALHAES, R. O. Resiliência: a ênfase nos fatores positivos. In: LIMA, C. A. (Coord.). Violência faz mal à saúde. Brasília: Ministério da Saúde, 2006. p. 275-265. 
AZEVEDO, M. A.; GUERRA, V. N. A. As políticas e a violência doméstica contra crianças e adolescentes: um desafio recusado em São Paulo? In:

Infância e Violência Doméstica: fronteiras do conhecimento. São Paulo: Cortez. 2011. p. 241-324.

BRASIL. Ministério da Justiça. Estatuto da Criança e do Adolescente. Lei Federal 8.069 de 1990, Brasília, 1990. Disponível em: <http://www.planalto.gov. br/ccivil 03/Leis/L8069.htm>. Acesso em: 17 nov. 2011.

BRITO, A. M. M. et al. Violência doméstica contra crianças e adolescentes: estudo de um programa de intervenção. Ciência \& Saúde Coletiva, [S.1.], v. 10, n. 1, p. 143-149, 2005.

BRUSCHINI, C. Teoria Crítica da Família. In: AZEVEDO, M. A.; GUERRA, V. N. A. (Org.). Infância e violência doméstica: fronteiras do conhecimento. São Paulo: Cortez, 2011. p. 56-86.

CHAUÍ, M. Contra a violência. 08 abr. 2007. Disponível em: <http://seaffilosofia.blogspot.com.br/2007/04/contra-violncia-por-marilena-chaui.html>. Acesso em: 21 nov. 2011.

COSTA, M. C; BIGRAS, M. Mecanismos pessoais e coletivos de proteção e promoção da qualidade de vida para a infância e adolescência. Ciência \& Saúde Coletiva, [S.1.], v. 12, n, 5, p. 1101-1109, set./out. 2007.

CYRULNIK, B. Falar de amor à beira do abismo. São Paulo: Martins Fontes, 2006.

DELL'AGLIO, D. D. et al. Revisando o questionário da juventude brasileira: uma nova proposta. In: DELL'AGLIO, D. D.; KOLLER, S. H. (Org.). Adolescência e Juventude: vulnerabilidade e contextos de proteção. São Paulo: Casa do Psicólogo, 2011.

DRANKA, R. A. P. Linguagem como mediação entre a vontade do Eu e do outro. Linguagem em (Dis)curso, v. 1, n. 2, 2001.

FALEIROS, V. P.; FALEIROS, E. S. Escola que Protege: enfrentando a violência contra crianças e adolescentes. Brasília: Ministério da Educação, 2007.

GOMES, R. et al. Porque as crianças são maltratadas? Explicações para a prática de maus-tratos infantis na literatura. Caderno de Saúde Pública, v. 18, n. 3, p. 707-714, maio/jun. 2002. 
LIBÓRIO, R. M. C.; CASTRO, B. M. Juventude e sexualidade: educação afetivo-sexual na perspectiva dos estudos da resiliência. In: LIBÓRIO, R. M. C.; KOLLER, S. H. (Org.). Adolescência e juventude: risco e proteção na realidade brasileira. São Paulo: Casa do Psicólogo, 2009. p. 185-217.

OSTERNE, M. S. F. Família, pobreza e gênero: o lugar da dominação masculina. Fortaleza: EDUECE, 2001.

SANCHEZ, R. N.; MINAYO, M. C. S. Violência contra crianças e adolescentes: questão histórica, social e de saúde. In: - Violência faz mal à saúde. Brasília: Ministério da Saúde, 2006. p. 29-38.

VYGOTSKY, L. S. Obras Escogidas: problemas del desarrollo de la psique (1927). Madrid: Visor, 1995. Tomo III.

VYGOTSKY, L. S. Internalização das funções psíquicas superiores. In: A formação social da mente. São Paulo: Martins Fontes, 2007. p. 51-58.

WAISELFISZ, J. J. Mapa da violência 2011: os jovens do Brasil. São Paulo: Instituto Sagari, 2011.

YUNES, M. A. M. Jovens: escolhas e mudanças - promovendo comportamentos saudáveis em adolescentes. Organização Pan-Americana da Saúde, 2003.

YUNES, M. A. M.; SZYMANSKI. Resiliência: noção, conceitos afins e considerações críticas. In: TAVARES, J. (Org.). Resiliência e educação. São Paulo: Cortez, 2001. p. 13-42.

Recebido em: 20 de maio de 2012 Aceito em: 11 de junho de 2014 